\title{
Convenção 169 da OlT e a livre determinação dos povos: protocolos autônomos de consulta como estratégia jurídica diante das ameaças aos territórios tradicionais
}

Convention 169 and the free determination of peoples: autonomous protocols consultation as legal strategy in face of threats to traditional territories

Liana Amin Lima da Silva ${ }^{1}$

Resumo: A Convenção 169 da OIT representa no âmbito internacional um marco normativo que supera o paradigma do indigenismo integracionista. De forma inédita, consagra o direito de autoatribuição e direitos de consulta e consentimento livre, prévio e informado. Diante da inobservância pelo Estado Brasileiro, os processos de construção de protocolos autônomos de consulta por povos e comunidades tradicionais nos últimos anos, inspira a reflexão sobre a convergência da saída jurídica apontada pelos povos e a compreensão do direito de decidir as prioridades no processo de desenvolvimento que lhes afetem, consubstanciada no reivindicado "direito de veto",

1 Professora de Direitos Humanos e Fronteiras (FADIR/ UFGD). Doutora em Direito Socioambiental e Sustentabilidade (PUCPR). Pós-Doutoranda em Direito (PUCPR). Coordenadora do Projeto (CNPq Universal) Observatório de Protocolos Comunitários de Consulta Prévia, Livre e Informada: Direitos territoriais, autodeterminação e jusdiversidade. 
o direito de dizer "não" como forma de se reconquistar a liberdade usurpada e de se reafirmar a livre determinação. O presente artigo foi elaborado com base na pesquisa doutoral "Consulta prévia e livre determinação dos povos indígenas e tribais na América Latina: re-existir para co-existir" (SILVA, 2017). Para a compreensão do direito de consulta e os protocolos próprios, fez-se necessária a abordagem sobre a importância da Convenção 169 para a luta e conquista dos direitos dos povos. À partir da conferência ministrada no Congresso "The struggle for Socio-environmental Rights: Brazil and Canada in solidarity", na Bishop's University, Sherbrooke, Québec, Canada, 2017, como opção metodológica, buscamos trazer à tona a problemática de conflitos socioambientais, com os exemplos de dois casos envolvendo mineradoras canadenses em territórios indígenas e tradicionais na Amazônia brasileira, destacando-se, nesse sentido, o Protocolo de Consulta Juruna da Terra Indígena de Paquiçamba da Volta Grande do Rio Xingu.

Palavras-chave: Consulta; consentimento; Protocolos; Povos indígenas e tradicionais.

ABSTRACT: Convention 169 of the ILO represents at the international level a normative framework that surpasses the paradigm of the integrationist. In an unprecedented way, it enshrines the right of selfattribution and rights of consultation and free, prior and informed consent. In the face of non-observance by the Brazilian State, the processes of constructing autonomous consultation protocols by traditional peoples and communities in recent years inspire reflection on the convergence of the output pointed out by the peoples and the understanding of the right to decide the priorities in the development process that the right to say "no" as a way to regain usurpated freedom and to reaffirm self-determination. This article was prepared based on the doctoral research "Prior consultation and free determination of indigenous and tribal peoples in Latin America: re-exist to co-exist" (SILVA, 2017). In order to understand the right of consultation and its own protocols, it was necessary to approach the importance of Convention 169 for the struggle and conquest of the rights of peoples. As a methodological option, as a methodological option, at the Bishop's 
University Conference, "The struggle for Socio-environmental Rights: Brazil and Canada in solidarity", at Bishop's University, Sherbrooke, Québec, Canada, 2017. Because of this, we sought to raise the issue of examples of two cases involving Canadian mining companies in indigenous and traditional territories in the Brazilian Amazon. In this sense, the consultation protocol of the Juruna people of the Indigenous Land of Paquiçamba of the Volta Grande of the Xingu River stands out.

Keywords: Consultation; consent; Protocols; Indigenous and traditional peoples.

\section{INTRODUÇÃO}

A Convenção 169 da OIT sobre Povos Indígenas e Tribais em Países Independentes (1989) ao revisar a Convenção 107 (1957), inaugura o reconhecimento dos chamados "novos" direitos desses povos (YRIGOYEN FAJARDO, 2011), ao prever o critério da autoatribuição - autorreconhecimento da identidade étnica ou tribal-, enfatizando os direitos territoriais e direitos de participação, consulta e consentimento prévio, livre e informado. Avanços esses que foram corroborados com a Declaração das Nações Unidas sobre os Direitos dos Povos Indígenas (ONU, 2007). Assim como, com a Declaração Americana sobre os Direitos dos Povos Indígenas, da Organização dos Estados Americanos (OEA, 2016).

Contudo, a situação de graves violações de direitos dos povos indígenas, quilombolas e tradicionais no Brasil tem se agravado na conjuntura da hegemonia de um projeto político que representa interesses neoliberais e retrocessos para o Estado Democrático de Direito, ao ameaçar os direitos e garantias fundamentais, constitucionalmente consagrados. Após o golpe parlamentar ocorrido no Brasil em 2016, o cenário das violações de direitos socioambientais se agravou, sobretudo com ataques aos direitos constitucionais indígenas e quilom- 
bolas, assim como ameaças de implementação de megaprojetos de exploração mineral em territórios de povos indígenas e tradicionais, na Amazônia brasileira.

As lições de luta e resistência dos povos indígenas e tradicionais apontam para o caminho da interculturalidade, com a concepção do que poderia ensejar uma transição para um sistema democrático intercultural. Para Catherine Walsh (2009, p.40-41), interculturalidade significa, de forma geral, o contato e intercâmbio entre culturas em termos equitativos e condições de igualdade, onde as diferenças constitutivas da sociedade passam a ser vistas como elemento de complementaridade e unidade, mas não de divisão.

O presente artigo foi elaborado à partir da conferência ministrada no congresso "The struggle for Socio-environmental Rights: Brazil and Canada in solidarity", na Bishop's University. Sherbrooke, Québec, Canada. October, 19-22, 2017, o que justifica o recorte de abordagem em relação à problemática das ameaças das mineradoras canadenses em territórios indígenas na Amazônia brasileira, bem como os apontamentos, de forma didática, sobre quem são os sujeitos coletivos de direito, da Convenção 169 da OIT, no Brasil.

Para a compreensão do direito de consulta e consentimento livre, prévio e informado, utilizou-se da metodologia da Investigación Acción Participativa, resgatando as lições de Fals Borda (1978). O levantamento e atualização de dados sobre a construção de protocolos autônomos de consulta, foi realizado no âmbito do Projeto de Pesquisa (Universal CNPq): Observatório de Protocolos de Consulta Prévia, Livre e Informada: direitos territoriais, autodeterminação e jusdiversidade, coordenado pela autora.

Para a compreensão do direito de consulta e consentimento livre, prévio e informado e do processo de construção dos protocolos autônomos de consulta como instrumentos jurídicos que refletem o exercício da livre determinação dos povos, buscou-se uma abordagem decolonial do direito (WALSH, 2009; SILVA, 2017) e compreensão sobre jusdiversidade, com base em SOUZA FILHO (2010; 1998). 


\section{BREVE INTRODUÇÃO SOBRE A CONVENÇÃO 169 DA OIT E A LUTA DOS POVOS PARA A COMPREENSÃO DO SENTIDO DA AUTODETERMINAÇÃO E COEXISTÊNCIA}

Lhie LIPIRIKANAA 169 IKAITEKADA NAMATSIATAKAA NADEENHIKAA NAKO NHAAHA NAWIKINAI HAMOLI 1989 (Trad. Língua BANIWA)

PA'MURI MAHSA, MAHSA KURARI KAHÃSERE, WIORÃ NEREKE'A UKŨ A'MESHOKARORE (CONVENÇÃO No 169 OIT) DA'RASE PEHE DI'TARI NA AHPOKŨKARO (Trad. Língua TUKANO)

A Convenção 169 da OIT sobre Povos Indígenas e Tribais avançou no reconhecimento dos direitos de participação e consulta prévia, reconhecimento da autonomia indígena e jurisdições próprias, amparada na noção de território e territorialidade, conferindo o poder de decisão (direito de consentimento) aos povos, a fim de garantir sua integridade étnico-cultural.

Como Huaco Palomino (2015, p. 54) observa, a definição do conteúdo do artigo $1^{\circ}$ da Convenção 169 marcou uma das controversas internacionais mais importantes no que concerne aos direitos dos povos indígenas, com a abordagem da questão da subjetividade internacional enquanto povos, assim como o alcance de seu direito coletivo à livre determinação.

A anterior Convenção, Convenção n. 107 da OIT, de 1957, concernente à Proteção e Integração das Populações Indígenas e de outras Populações Tribais e Semitribais de Países Independentes, expressava preocupação com a proteção das populações indígenas em tom tutelar, com a finalidade da integração progressiva das populações aos respectivos países. Baseava-se na questão étnica como moral, seguindo a ótica de tutela indígena, ou seja, os indíge- 
nas tratados como incapazes e em vias de integração e assimilação à sociedade nacional.

Segundo Mariátegui (2010, p. 57-58), "a suposição de que o problema indígena é um problema ético se nutre do repertório mais envelhecido das ideias imperialistas. $O$ conceito de raças inferiores serviu ao Ocidente branco para sua obra de expansão e conquista."

Díaz-Polanco (2006) expõe sobre a transição das práticas abertamente etnocidas para a etnofagia, mediante a qual a cultura de dominação busca engolir ou devorar as múltiplas culturas populares, principalmente em virtude da força de gravitação que os padrões nacionais exercem sobre as comunidades étnicas: "Não se busca a destruição mediante a negação absoluta ou ao ataque violento, mas na dissolução gradual, utilizando-se dos aparatos de hegemonia do Estado nacional para atrair, deslocar e dissolver os grupos diversos".

A Convenção 107 refletia a política de dominação integracionista dos anos 1950, política paternalista e assimilacionista no marco de um ideal protecionista, o que expressava a crença que os povos indígenas eram transitórios. Segundo Magdalena Gómez (1995, p.12), isso significa que, ao considerá-los cidadãos, os povos indígenas teriam que desaparecer como tais.

A diretriz paternalista e integracionista já não podia seguir mantendo-se como princípio de relação entre Estados e povos indígenas, que deviam reconhecer o direito indígena a controlar o seu próprio desenvolvimento econômico e social.

Para Tauli-Corpuz (Prólogo, In:HUACO PALOMINO, 2015 p.23) , ao ser considerado o processo de elaboração da Convenção 169 em sua verdadeira perspectiva histórica, um resultado fundamental é a superação dos enfoques paternalistas e integracionistas do passado, substituídos pela consideração dos povos indígenas como sujeitos do seu próprio destino, no sentido do que determina o dever dos Estados de adotar medidas especiais para terminar com séculos de discriminação.

Assim, a Convenção 169 ao revogar a Convenção 107, representa a conquista dos denominados "novos" direitos dos povos e comunidades tradicionais. Agora não mais amparados na ótica assimilacionista, mas 
sim no reconhecimento de suas autonomias e sua autoconsciência, ou seja, a consciência de sua identidade étnico-cultural (indígena ou tribal).

Durante a Reunião da Comissão Internacional do Trabalho encarregada de revisar a Convenção, o Indigenous People's Working Group of the Canadian Association of Geographers (IPWG) demonstrou que o emprego do termo "povos" era necessário para consolidar o reconhecimento do direito desses grupos a sua identidade e como prova essencial de uma mudança de orientação para um maior respeito das suas culturas e modos de vida.

Nesse debate, é de se destacar o importante discurso da sra. Sayers, representante indígena, participando como conselheira técnica dos trabalhadores do Canadá:

[...] Los términos «pueblos» y "territorios» han sido condicionados y clasificados. Nuestras leyes consuetudinarias no se reconocen ni se respetan; nuestros derechos inherentes al consentimiento se diluyeron en consultas. No, nosotros, como pueblos indígenas, no tenemos que aceptar esto, y no lo aceptamos. [...] Los objetivos de la revisión consistían en armonizar ese Convenio con los progresos realizados en el derecho internacional y anular la orientación de asimilación. Estos objetivos no se han logrado. El proyecto de convenio propende a la asimilación de manera sutil mientras que el anterior lo hacía de manera muy flagrante. $Y$ en vez de ser un instrumento de vanguardia en el campo del derecho internacional, tenemos un instrumento que no logra reflejar las tendencias nuevas del derecho internacional. (Actas provisionales $n^{\circ}$. 31, 34a sesión, 26 de junio de 1989. In: HUACO PALOMINO, 2015, p.52).

Do mesmo modo, o representante da Conferência Inuit Circumpolar demonstrou a importância fundamental de se reconhecer as diversas sociedades indígenas como povos. declarou que se se seguisse utilizando o termo populações, estaria enterrada a credibilidade do processo de revisão, pois os povos indígenas continuariam sendo descritos em termos inadequados e imprecisos. (HUACO PALOMINO, 2015, p.69). 
Ainda que representantes indígenas e da sociedade civil canadense tenham participado ativamente das discussões para revisão da Convenção 107 e elaboração da Convenção 169 no âmbito da OIT, destaca-se que o Canadá até os dias atuais não ratificou a Convenção. Entre os 22 Estados que ratificaram a Convenção, 16 são Estados latino-americanos, 01 da Oceania, 01 africano, 01 asiático e 03 europeus. A Convenção 169 passa a ter força vinculante para os países que a ratificam.

No Brasil foi ratificada em 2002, promulgada pelo Decreto 5.501 de 2004, possui status "supralegal", quer dizer, está acima das leis e abaixo da Constituição. Enquanto que países latino-americanos como Bolívia e Colômbia, por se tratar de um tratado de direitos humanos, reconhecem que a Convenção integra o bloco de constitucionalidade.

Os sujeitos coletivos da Convenção 169 estão definidos no artigo 10: povos tribais em países independentes e povos considerados indígenas, em países independentes. $O$ artigo $1^{\circ}$ também dispõe sobre o critério da autoatribuição (autorreconhecimento) e faz a ressalva de que a utilização do termo "povos" não deverá ser interpretada no sentido conferido a esse termo no direito internacional.

A Convenção n. 169 define povos considerados indígenas, como aqueles que descendem de populações que habitavam o país ou uma região geográfica pertencente ao país na época da conquista ou colonização ou do estabelecimento das atuais fronteiras estatais e que, seja qual for sua situação jurídica, conservam todas as suas próprias instituições sociais, econômicas, culturais e políticas, ou parte delas (artigo $1^{\circ}-1, \mathrm{~b}$ ).

Os povos tribais, sujeitos da Convenção 169 (art. 1-1, a), são aqueles "cujas condições sociais, culturais e econômicas os distingam de outros setores da coletividade nacional, e que estejam regidos, total ou parcialmente, por seus próprios costumes ou tradições ou por legislação especial". 


\section{DIREITOS DOS POVOS INDÍGENAS, QUILOMBOLAS E COMUNIDADES TRADICIONAIS NO BRASIL}

Conforme CENSO IBGE 2010, dos povos indígenas no Brasil, foram identificadas 305 etnias, falantes de 274 línguas, sendo a população indígena de 896,9 mil, representando $0,44 \%$ da população total, conforme o último Censo 2010. ${ }^{2}$

Os direitos coletivos dos povos indígenas e comunidades tradicionais podem ser compreendidos como direitos territoriais, direitos culturais, direito à organização social própria, autonomia e autodeterminação, que inclui o direito à participação, consulta e consentimento livre prévio e informado.

Os direitos dos povos indígenas estão previstos em capítulo especial na Constituição brasileira de 1988 (artigos 231, parágrafos e 232), que reconhece sua organização social, costumes, crenças, tradições e os direitos originários das terras que tradicionalmente ocupam. Os direitos territoriais das comunidades quilombolas estão previstos no art. 68 do Ato das Disposições Constitucionais Transitórias (ADCT).

No Brasil os sujeitos da Convenção 169 "povos indígenas e tribais" são identificados como "povos e comunidades tradicionais". O Decreto n. 6.040, de 07 de fevereiro de 2007, dispõe sobre a Política Nacional de Desenvolvimento Sustentável dos Povos e Comunidades Tradicionais (PNPCT). Observando o critério da autoatribuição, define povos e comunidades tradicionais (Art. $\left.3^{\circ}, \mathrm{I}\right)$ como:

Grupos culturalmente diferenciados e que se reconhecem como tais, que possuem formas próprias de organização social, que ocupam e usam territórios e recursos naturais como condição para sua reprodução cultural, social, religiosa, ancestral e eco-

2 BRASIL. CENSO 2010. Indígenas. Instituto Brasileiro de Geografia e Estatística [IBGE]. Disponível em:< http://indigenas.ibge.gov.br/>. Acesso em 10 de janeiro de 2017. 
nômica, utilizando conhecimentos, inovações e práticas gerados e transmitidos pela tradição. ${ }^{3}$

Destacam-se os grupos que compuseram o Conselho Nacional de Povos e Comunidades Tradicionais (CNPCT): povos indígenas, comunidades quilombolas, povos e comunidades de terreiro/ povos e comunidades de matriz africana, povos ciganos, pescadores artesanais, extrativistas, extrativistas costeiros e marinhos, caiçaras, faxinalenses, benzedeiros, ilhéus, raizeiros, geraizeiros, caatingueiros, vazanteiros, veredeiros, apanhadores de flores sempre vivas, pantaneiros, morroquianos, povo pomerano, catadores de mangaba, quebradeiras de coco babaçu, retireiros do Araguaia, comunidades de fundos e fecho de pasto, ribeirinhos, cipozeiros, andirobeiros, caboclos. ${ }^{4}$

O Decreto $n^{\circ} 4.887$, de 20 de novembro de 2003 - que trata dos procedimentos de titulação e demarcação de terras quilombolas -, define em seu artigo 20: "Consideram-se remanescentes das comunidades dos quilombos, para os fins deste Decreto, os grupos étnico-raciais, segundo critérios de auto-atribuição, com trajetória histórica própria, dotados de relações territoriais específicas, com presunção de ancestralidade negra relacionada com a resistência à opressão histórica sofrida." ${ }^{5}$

3 BRASIL. Decreto $n^{\circ} \mathbf{6 . 0 4 0}$ de 07 de fevereiro de 2007. Institui a Política Nacional de Desenvolvimento Sustentável dos Povos e Comunidades Tradicionais. Disponível em:< http://www.planalto.gov.br/ccivil_03/_ato2007-2010/2007/decreto/d6040.htm>. Acesso em 10 de janeiro de 2017.

4 Com base em: BRASIL, Decreto 8.750 de 09 de maio de 2016. Institui o Conselho Nacional dos Povos e Comunidades Tradicionais. Registra-se que, de forma arbitrária, o governo Bolsonaro, por meio de um decreto notadamente inconstitucional, extinguiu o Conselho Nacional de Povos e Comunidades Tradicionais (CNPCT), o Conselho Nacional de Política Indigenista (CNPI) e diversos órgãos colegiados que concretizavam o exercício da democracia participativa. (BRASIL. Decreto n. 9.759, de 11 de abril de 2019. Extingue e estabelece diretrizes, regras e limitações para colegiados da administração pública federal. Disponível em: http://www.planalto.gov.br/ccivil_03/_ato2019-2022/2019/decreto/ D9759.htm. Acesso em: 12 abr. 2019).

5 BRASIL, Decreto 4.887, de 20 de novembro de 2003. Regulamenta o procedimento para identificação, reconhecimento, delimitação, demarcação e titulação das terras ocupadas por remanescentes das comunidades dos quilombos de que trata o art. 68 do Ato das Disposições Constitucionais Transitórias. 
Com o reconhecimento constitucional, as comunidades quilombolas tornam-se visíveis perante o Estado, a partir da perspectiva da sobrevivência e resistência à opressão sofrida, como categoria jurídica de acesso à direitos coletivos e reparação da opressão histórica que sempre negou os direitos de existência e de liberdade, a liberdade de se autodeterminar segundo seus modos de vida e tradições.

Ressalta-se que o reconhecimento dos direitos dos povos e comunidades tradicionais pelo Estado brasileiro só tem sido possível com a luta, reivindicação e pressão dos próprios povos e comunidades tradicionais.

Tal movimento, em geral, surge e se consolida diante do enfrentamento de uma ameaça comum, diante de um conflito socioambiental que ameaça sua existência tradicional com a usurpação da terra e destruição ou contaminação da natureza, necessitando defender e reivindicar o reconhecimento, demarcação e titulação do território tradicional coletivo.

Diante de omissões do Estado brasileiro para se aplicar os direitos já reconhecidos, a luta dos povos e comunidades para se efetivar a proteção jurídica garantida pela Convenção 169 não tem sido diferente. A Articulação dos Povos Indígenas do Brasil (APIB) e a Coordenação Nacional de Articulação das Comunidades Quilombolas (CONAQ) possuem um papel fundamental, sobretudo com a denominada Mobilização Nacional Indígena e Quilombola.

No Brasil, as organizações nacionais representativas dos povos indígenas e quilombolas desde 2008 articulam diretamente com a Central Única dos Trabalhadores (CUT) - Brasil, para os encaminhamentos e denúncias de descumprimento da Convenção 169 da OIT, denunciando 05 (cinco) casos emblemáticos: UHE de Belo Monte; Terra Indígena dos Guarani e Kaiowá; Terra Indígena Raposa Serra do Sol; Mineração em Terra Indígena dos Cinta Larga e Transposição do Rio São Francisco.

\footnotetext{
A Comunicação dos indígenas optou por analisar o cumprimento da Convenção 169 a partir de quatro temas estruturantes da proble-
} 
mática indígena no Brasil: identidade étnica; consulta e participação; direitos territoriais e recursos naturais; desenvolvimento.

Além dos casos emblemáticos citados, a Comunicação dos povos indígenas também denunciou as medidas legislativas inconsultas, (7) Propostas de Emenda Constitucionais e (42) Projetos de Lei que dispõem de temas de relevante interesse aos povos indígenas. Denunciou a paralização da tramitação do Projeto de Lei do Estatuto dos Povos Indígenas (desde 1991) e a ameaça do Projeto de Lei n. 1.610 de 1996, sobre mineração em terras indígenas.

Na mesma ocasião, a CUT encaminhou a Comunicação das Comunidades Quilombolas, assinada pela Coordenação Nacional de Articulação das Comunidades Negras Rurais Quilombolas (CONAQ). A Comunicação Quilombola enfatizou sobre a aplicabilidade da Convenção 169 da OIT aos Quilombolas, denunciando casos de violação ao critério da auto-identificação, consulta e participação e aos direitos territoriais, com a ausência e morosidade na titulação de terras quilombolas, pelo Estado brasileiro.

Ressalta-se que em abril de 2017, ocorreu a maior mobilização da história do movimento indígena brasileiro, concretizada por meio do Acampamento Terra Livre (ATL) 2017 em Brasília, DF. Os representantes e lideranças das diversas etnias manifestaram contra os retrocessos de direitos socioambientais, denunciando o sucateamento da política indigenista e o golpe de Estado. Na ocasião, o movimento indígena foi alvo de violenta repressão pelo aparato policial do Estado brasileiro.

No Brasil, agrava-se o cenário dos conflitos socioambientais, onde os povos indígenas, quilombolas e comunidades tradicionais permanecem invisibilizados e excluídos dos processos de decisões que lhes afetem. Quando há participação dos povos, tal participação acaba por revelar processos hegemônicos de subalternização dos grupos étnicos ou cooptação de lideranças, com a dominação do discurso de desenvolvimento e interesse nacional, quando melhor seria defini-lo como interesses do capital. 


\section{AMEAÇAS DE MINERADORAS CANADENSES EM TERRAS INDÍGENAS E TRADICIONAIS NA AMAZÔNIA E A VIOLAÇÃO DO DIREITO DE CONSULTA E CONSENTIMENTO LIVRE, PRÉVIO E INFORMADO}

Na Amazônia brasileira, mineradoras canadenses tem representado uma grave ameaça aos direitos territoriais de povos indígenas, quilombolas, comunidades ribeirinhas e tradicionais. Dois casos merecem destaques, o caso da Terra Indígena Alto Rio Negro, Amazonas, ameaçada pelas investidas da mineradora canadense Cosigo e o caso do megaprojeto Belo Sun, em Altamira-Pará, na volta Grande do Xingu, região já impactada pelo empreendimento hidrelétrico de Belo Monte.

A Terra Indígena Alto Rio Negro, além de representar uma região de megabiodiversidade, conforma a região mais plurilíngue do continente americano, com um sistema ecolinguístico de 23 diferentes línguas indígenas de cinco troncos linguísticos: Tupi (Nheegatu), Tukano Oriental (Tukano, Tuyuka, Desana, Wanano, Piratapuya, etc.), Aruak (Baniwa, Kuripako, Tariano, Werekena) e Maku (Nadëb, Daw, Yuhup, Hupda), Yanomami, além de duas línguas de família românica, o Português e o Espanhol. ${ }^{6}$ Nesta região, localiza-se São Gabriel da Cachoeira - AM, o município de maior população indígena do Brasil.

6 Os indígenas Tukano Oriental e Aruak vivem em comunidades dispersas ao longo dos rios e seus tributários navegáveis. Sua territorialidade está ligada ao rio e por isto são chamados "índios do rio" e a dos povos Hupdah, Yuhup, Dâw e Nadêb e Yanomami está relacionada à floresta; por isto são conhecidos como "índios do mato". Os indígenas da família Tukano Oriental (Arapaço, Bara, Barasana, Desana, Kubeo, Karapanã, Makuna, Miriti-tapuia, Piratapuia, Siriano, Taiwano, Tatuyo, Tukano, Tuyuka, Yuriti, Wanano) ocupam um território único limitado pela rede hidrográfica do Uaupés e seus afluentes e pelo rio Pira-Paraná, na Colômbia, que pertence à rede hidrográfica Paporis-Caquetá. Os indígenas da família Aruak, Baniwa, Kuripako, Baré, Werekena (alto Rio Negro e Xié) e os Tariano (Baixo Rio Uaupés), espalhamse ao longo do rio Içana e seus afluentes (rios Cuiary, Aiary e Cubate), do Alto Rio Negro entre São Gabriel da Cachoeira e San Carlos del Rio Negro (Venezuela) ao Baixo rio Xié entre três países Brasil, Colômbia e Venezuela. Os índígenas Hupdah, Yuhup, Dâw e Nadêb são seminômades caçadores, coletores e vivem nas zonas de interflúvios de difícil acesso dos rios Papuri e Tiquié ou na floresta ao sul do rio Tiquié, longe dos rios e igarapés navegáveis. 
Em se tratando de projetos de extração mineral em áreas protegidas, são 104 processos titulados e 4.116 interesses minerários que incidem sobre 152 Terras Indígenas localizadas na Amazônia Legal (ISA, 2013). Tramitam no Congresso Nacional, desde 1996, o Projeto de Lei de Mineração em Terras Indígenas (PL 1610/1996) e o Projeto de Lei do novo Código da Mineração (PL n. 5807 de 2013).

$\mathrm{Na}$ Terra Indígena Alto Rio Negro, no ano de 2013, registrou-se 386 processos para exploração mineral que tramitam no Departamento Nacional de Produção Mineral (DNPM). Paralelamente, a tramitação do Projeto de Lei (PL) 1610/1993 sobre Mineração em Terras Indígenas e do projeto do novo Código de Mineração, sem participação dos povos indígenas e sem consulta prévia, torna-se uma ameaça a nível nacional. ${ }^{7}$

Quadro 3: Incidência de processos para exploração mineral na região do Alto Rio Negro.

Departamento Nacional de Produção Mineral (DNPM)

\begin{tabular}{|l|l|l|l|l|}
\hline Terra Indígena & $\begin{array}{l}\text { Extensão } \\
\text { oficial (ha) }\end{array}$ & Processos & $\begin{array}{l}\text { Área da } \\
\text { TI com } \\
\text { incidência }\end{array}$ & $\begin{array}{l}\text { \% da TI } \\
\text { coberta por } \\
\text { processo }\end{array}$ \\
\hline ALTO RIO NEGRO & 7.999 .380 & 386 & 3.055 .808 & $38,02 \%$ \\
\hline YANOMAMI & 9.664 .980 & 657 & 5.228 .959 & $54,77 \%$ \\
\hline
\end{tabular}

Fonte: ROLLA, Alicia; RICARDO, Fany (org.). Mineração em Terras Indígenas na Amazônia Brasileira. Instituto Socioambiental (ISA), 2013.

A mesma empresa mineradora canadense - Cosigo Frontier Mining Corporation - que firmou intenção de explorar mineração no Alto Rio Negro, teve sua atuação questionada por violar o direito a consulta e ao consentimento livre, prévio e informado nas fronteiras do alto rio Negro, no território colombiano (Departamento de Vaupés). Confor-

Disponível em: UFAM. Política Linguística. Licenciatura Indígena Políticas Educacionais e Desenvolvimento Sustentável - Universidade Federal do Amazonas (UFAM).

7 Nesse sentido, recomenda-se: Environmental Justice Atlas. Lobbying for the new Mining Code and cooptation of indigenous communities along Rio Negro, Amazonas, Brazil. Disponível em: <https://ejatlas.org/conflict/indigenous-communities-of-rio-negro-dividedover-mining-regularization-and-affected-by-commercial-cooptation-and-illegal-mining>. Acesso em 20 de abril de 2019. 
me ação de tutela interposta pela Asociación de Capitanes Indígenas del Resguardo Yaigojé Apaporis (ACIYA), resultando na sentença T-384A/2014 da Corte Constitucional colombiana. ${ }^{8}$

Diante da ameaça de conflitos socioambientais e frequente cooptação de indígenas em prol dos interesses dos investimentos na exploração mineral na região, a Federação das Organizações Indígenas do Rio Negro (FOIRN), instância política, com personalidade jurídica para representatividade dos 23 povos do rio Negro, tem se articulado para a reafirmação dos direitos fundamentais dos povos, com a denúncia da violação do direito de consulta e consentimento livre, prévio e informado, ferindo a Constituição Federal (artigo 231, § $3^{\circ}$.) e Convenção n. 169 da OIT.

O segundo caso que destacamos, extremamente grave, envolve o processo de licenciamento ambiental para instalação da mineradora de ouro Belo Sun Mining Corporation na região de Altamira, Pará, atingindo os territórios indígenas e ribeirinhos já impactados e devastados pelo megaprojeto hidrelétrico de Belo Monte.

O processo de licenciamento ambiental no âmbito da Secretaria de Meio Ambiente do Pará, violou o direito de consulta prévia, livre e informada. Diante do histórico de violações e ameaças sofridas, o povo Juruna de Paquiçamba elaborou seu protocolo de consulta, destacando:

Não aceitaremos qualquer projeto que nos afaste do rio Xingu ou inviabilize nossa permanência no rio. Nós não fomos consultados para a construção da Hidrelétrica de Belo Monte, que desviou o rio Xingu de nossa terra para usar sua água na produção de energia. Com a construção da usina, perdemos nossa principal fonte de alimentação e renda, que era a pesca artesanal e de peixes ornamentais. Não sabemos como ficarão o rio, os bichos, a floresta e nem a gente daqui para frente. (PROTOCOLO JURUNA, 2017)

No Protocolo de Consulta do povo Juruna (Yudjá) da TI Paquiçamba, é possível encontrar as regras e diretrizes para um processo de consulta, com as seguintes questões explicitadas pelo povo Juruna:

8 COLOMBIA, Corte Constitucional. Sentencia T-384A/14. Referencia: expediente T-2.650.067. Magistrado ponente: Gabriel Eduardo Mendonza Martelo. Bogotá, D.C., 17 de junio de 2014. 
Sobre o que o governo é obrigado a nos consultar? Quando o governo deve nos consultar? Como devemos ser consultados? Quem deve participar das consultas? Como as reuniões devem ser realizadas? Quem pode convocar as reuniões de consulta? Quais reuniões acontecerão durante o processo de consulta? Como devem ser discutidas as informações durante a consulta? O que é o Plano de Consulta? Como nós tomamos decisões? Como se encerra o processo de consulta? (PROTOCOLO JURUNA, 2017)

Em julgamento de 06 de dezembro de 2017, o Tribunal Regional Federal da 1a. Região (TRF1), suspendeu o licenciamento da mineradora canadense Belo Sun e ordenou a realização da consulta prévia, livre e informada aos indígenas afetados pelo empreendimento, nos moldes do que é previsto na Convenção 169 da OIT. ${ }^{9}$

A decisão faz referência e reconhece que o processo de consulta deverá observar o protocolo elaborado pelos próprios indígenas. Destaca-se a relevância do precedente, pois trata-se do primeiro caso em que o Judiciário brasileiro reconheceu um protocolo autônomo de consulta, como instrumento que dita as regras que deverá orientar os processos e planos de consulta e consentimento livre, prévio e informado. ${ }^{10}$

\section{PROTOCOLOS AUTÔNOMOS DE CONSULTA À LUZ DA JUSDIVERSIDADE}

O direito à livre determinação é um direito humano sem o qual um povo não realiza e exerce os demais direitos, já que em virtude desse direito determinam livremente seu estatuto político e asseguram livremente seu desenvolvimento econômico, social e cultural (Declaração

9 MPF. Notícias. TRF1 ordena consulta prévia a indígenas afetados pela mineradora Belo Sun e mantém suspensão do licenciamento. Disponível em: <http://www. $\mathrm{mpf} . \mathrm{mp} . \mathrm{br} / \mathrm{pa} / \mathrm{sala}$-de-imprensa/noticias-pa/trf1-ordena-consulta-previa-a-indigenasafetados-pela-mineradora-belo-sun-e-mantem-suspensao-do-licenciamento> . Acesso em 20 de setembro de 2018.

10 BRASIL. Justiça Federal. Tribunal Regional Federal da $1^{a}$ Região. Apelação Cível $\mathbf{n}$. 0002505-70.2013.4.01.3903/PA. Relator Desembargador Federal Jirair Aram Meguerian.

Decisão de 06 dez. 2017. 
das Nações Unidas sobre os Direitos dos Povos Indígenas (artigo 3), Pacto Internacional sobre Direitos Econômicos, Sociais e Culturais (artigo 1) e Pacto Internacional sobre Direitos Civis e Políticos (artigo 1).

Resgatando as lições dos debates nos trabalhos preparatórios da Convenção 169, verifica-se que, ainda que os termos "autodeterminação" e "livre determinação" não apareçam expressamente no texto, o seu conteúdo encontra-se preenchido.

Ressalta-se que a interpretação dos direitos previstos na Convenção 169, deve ser feita à luz da Declaração das Nações Unidas sobre os Direitos dos Povos Indígenas (ONU, 2007) e Declaração Americana (OEA, 2016).

A Declaração (ONU, 2007) dispõe, em seu artigo 3 que "os povos indígenas têm direito à autodeterminação. Em virtude desse direito determinam livremente seu desenvolvimento econômico, social e cultural". O artigo 4 dispõe que "os povos indígenas, no exercício do seu direito à autodeterminação, têm direito à autonomia ou ao autogoverno nas questões relacionadas a seus assuntos internos e locais, assim como disporem dos meios para financiar suas funções autônomas".

Assim, a liberdade de determinar-se enquanto povo, definindo os caminhos e o futuro de sua existência deve ser reconhecida e respeitada externamente. A autodeterminação conduz à noção de jusdiversidade.

Souza Filho (2010, p. 191) denomina como jusdiversidade a liberdade de agir de cada povo segundo suas próprias leis, seu direito próprio e sua jurisdição.

A autodeterminação abrange o conceito de autonomia territorial. A autonomia pode ser compreendida também em suas facetas cultural, epistemológica, linguística, política e econômica. A jusdiversidade, portanto, se baseia na diversidade cultural, diversidade de sistemas jurídicos próprios, que, por sua vez, se vincula a determinado território (jurisdição indígena, tradicional ou ancestral).

Diante da inobservância do direito de consulta prévia, uma saída jurídica apontada pelos povos é a construção de protocolos comunitários, também chamado de protocolo próprio, como um instrumento em 
que as comunidades expressam sua voz e seu direito próprio, como exercício da jusdiversidade e autodeterminação.

Em face do descumprimento e violação pelo Estado brasileiro na implementação do direito de consulta prévia, livre e informada, desde 2014, há um movimento e iniciativa por parte dos próprios povos e comunidades tradicionais em elaborarem seus protocolos de consulta. Registra-se a construção de diversos protocolos autônomos de consulta e consentimento livre, prévio e informado no Brasil, dos quais destacam-se:

\begin{tabular}{|c|c|}
\hline Protocolo de Consulta e Consentimento Wajãpi & 2014 \\
\hline Protocolo de Consulta Beiradeiros Montanha e Mangabal & 2014 \\
\hline Protocolo de Consulta Munduruku & 2014 \\
\hline Protocolo de Consulta Quilombola de Santarém & 2016 \\
\hline Protocolo de Consulta dos Povos do Território Indígena do Xingu & 2016 \\
\hline $\begin{array}{c}\text { Protocolo de Consulta dos Povos Munduruku e } \\
\text { Apiaká do Planalto Santareno }\end{array}$ & 2017 \\
\hline $\begin{array}{c}\text { Protocolo de Consulta aos Pescadores e } \\
\text { Pescadoras do município de Santarém-PA }\end{array}$ & 2017 \\
\hline Protocolo de Consulta Quilombolas de Abacatal/Aurá & 2017 \\
\hline $\begin{array}{c}\text { Protocolo de Consulta - Comunidade Tradicional } \\
\text { da Ponta Oeste, llha do Mel, Paraná }\end{array}$ & 2017 \\
\hline Protocolo de Consulta do Povo Krenak & 2017 \\
\hline $\begin{array}{c}\text { Protocolo de Consulta Juruna Yudjá da Terra Indígena } \\
\text { Paquiçamba da Volta Grande do Rio Xingu }\end{array}$ & 2017 \\
\hline $\begin{array}{c}\text { Protocolo de Consulta das Comunidades } \\
\text { Ribeirinhas Pimental e São Francisco }\end{array}$ & 2017 \\
\hline Protocolo de Consulta ao Povo Waimiri Atroari & 2018 \\
\hline $\begin{array}{c}\text { Protocolo de Consulta Prévia, Livre e Informada da } \\
\text { Comunidade Agroextrativista do Pirocaba/Abaetetuba - Pará }\end{array}$ & 2018 \\
\hline $\begin{array}{c}\text { Protocolo de Consulta e Consentimento da Associação das } \\
\text { Comunidades Remanescentes de Quilombo do Alto Trombetas II }\end{array}$ & 2018 \\
\hline Protocolo de Consulta Prévia da Tekoa Itaxi Mirim & 2018 \\
\hline Protocolo Kayapó-Menkrãgnoti & 2019 \\
\hline Protocolo de Consulta dos Povos do Oiapoque, Amapá & 2019 \\
\hline Bara
\end{tabular}

Fonte: Banco de dados do Observatório de Protocolos Comunitários de Consulta Prévia, Livre e Informada: Direitos territoriais, autodeterminação e jusdiversidade (Projeto CNPq Universal).

Disponível em: <http://direitosocioambiental.org/observatorio-de-protocolos/ protocolos-comunitarios-de-consulta/>. Acesso em: 08 de março de 2019. 
Os protocolos próprios contêm as regras mínimas e fundamentais que os povos e comunidades estabelecem e exteriorizam para a sociedade envolvente e para o Estado, apontando como se respeitar o direito próprio, suas jurisdições próprias e formas de deliberação e de organização social em um processo de consulta prévia.

Os protocolos autônomos, em geral, objetivam demonstrar como um processo de consulta deve ser realizado de forma legítima e apropriada, respeitando as particularidades culturais e as instituições representativas de cada povo ou comunidade. Trata-se, portanto, de um exercício de autodeterminação dos povos que deve ser observado e respeitado pelo Estado.

\section{CONSIDERAÇÕES FINAIS}

É dever do Estado consultar os povos indígenas e tribais quando qualquer ato ou medida de natureza legislativa ou administrativa os afete. A consulta deve ser prévia, culturalmente adequada e de boa-fé. Como pedra angular da Convenção 169, o direito à consulta prévia é um direito fundamental e está intrinsecamente ligado ao direito de consentimento livre, prévio e informado e à livre determinação.

O consentimento livre prévio e informado compõe o direito de decidir as prioridades no que concerne ao modelo de desenvolvimento que afete os povos indígenas e tribais/ tradicionais, configurando-se, portanto, uma expressão do direito à autodeterminação.

A consulta prévia não deve ser considerada como um mero procedimento ou formalidade a ser cumprida, deve ser encarada como um mecanismo que garante a vida e integridade física e cultural dos povos, de modo a prevenir e superar conflitos socioambientais em territórios tradicionais.

A consulta prévia é um direito fundamental e deve ser implementada visando um diálogo intercultural igualitário, com o objetivo de salvaguardar e garantir os direitos coletivos dos povos indígenas, quilombolas e comunidades tradicionais. 
A saída apontada pelos povos, com a construção de protocolos próprios de consulta e consentimento livre, prévio e informado, converge com o direito de decidir as prioridades no processo de desenvolvimento que lhes afetem, consubstanciada no reivindicado "direito de veto", o direito de dizer "não" como forma de se reconquistar a liberdade usurpada e reafirmar a livre determinação dos povos.

Os protocolos revelam-se como instrumentos de autodeterminação, portanto, vinculante aos Estados, na observância e implementação da consulta prévia, livre e informada. Logo, deve ser garantido aos povos indígenas, quilombolas e comunidades tradicionais apontar as alternativas ao modelo de desenvolvimento predatório, de modo que seja garantida sua coexistência dentro das fronteiras do Estado.

\section{REFERÊNCIAS}

DÍAZ-POLANCO, Héctor. Autonomía regional. La autodeterminación de los pueblos indios. Segunda edición aumentada, Mexico, D.F.: Siglo XXI editores, 2006.

ATLAS, Environmental Justice. Lobbying for the new Mining Code and cooptation of indigenous communities along Rio Negro, Amazonas, Brazil. Disponível em: <https://ejatlas.org/ conflict/indigenous-communities-of-rio-negro-divided-over-miningregularization-and-affected-by-commercial-cooptation-and-illegalmining>. Acesso em 20 de abril de 2019.

FALS BORDA, Orlando. Por la práxis: el problema de como investigar la realidad para transformarla. Federación para el Análisis de la realidad Colombiana (FUNDABCO). Bogotá, Colombia, 1978.

GÓMEZ, Magdalena. Derechos indígenas. Lectura comentada del Convenio 169 da la Organización Internacional del Trabajo. 2.ed. Xochimilco, México, D.F.: Instituto Nacional Indigenista, 1995.

GUAJAJARA, Sonia. Entrevista. É hora de ir pra cima, para o embate. Política. Carta Capital. Por Maria Emilia Coelho. Publicado em 28 de 
setembro de 2013. Disponível em: < http://www.cartacapital.com.br/ politica/201ce-hora-de-ir-para-cima-para-o-embate201d-4865.html> Acesso em 10 de janeiro de 2017.

HUACO PALOMINO, Marco Antonio. Los trabajos preparatorios del Convenio no. 169 sobre Pueblos Indígenas y Tribales en Países Independientes. Fundación Konrad Adenauer (KAS), Programa Regional de Participación Política Indígena (PPI) en América Latina. Lima, 2015.

JURUNA DA TI PAQUIÇAMBA. Protocolo de Consulta do povo Juruna (Yudjá) da TI Paquiçamba da Volta Grande do Rio Xingu. Ed. Luís Donisete Benzi Grupioni. Realização: Rede de Cooperação Amazônica (RCA), Instituto Socioambiental (ISA). Vitória do XinguPará, 2017. Disponível em: <https://www.socioambiental.org/sites/blog. socioambiental.org/files/nsa/arquivos/2017_protocolo_de_consulta_ juruna_completo.pdf>.

MAGALHÃES, Sônia Barbosa; CUNHA, Manuela Carneiro da (coord.). A expulsão de ribeirinhos em Belo Monte. Relatório da SBPC. São Paulo: SBPC, 2017.

MARIÁTEGUI, Sete ensaios de interpretação da realidade peruana. Tradução Felipe José Lindoso. 2a.ed. São Paulo: Expressão Popular, 2010.

ISA, INSTITUTO SOCIOAMBIENTAL. ROLLA, Alicia; RICARDO, Fany (org.). Mineração em Terras Indígenas na Amazônia Brasileira. São Paulo: Instituto Socioambiental (ISA), 2013.

SILVA, Liana Amin Lima da. Consulta prévia e livre determinação dos povos indígenas e tribais na América Latina: re-existir para co-existir. Tese de Doutorado em Direito Socioambiental. Pontifícia Universidade Católica do Paraná (PUCPR), Curitiba-PR, Brasil, 2017.

SOUZA FILHO, Carlos Frederico Marés de. 0 renascer dos povos indígenas para o Direito. 7. reimpr. Curitiba: Juruá, 2010. 
Autodeterminação dos povos e jusdiversidade. In: ALMEIDA, lleana; ARROBO RODAS, Nidia. (coord.). En defensa del pluralismo y la igualdad. Los derechos de los pueblos indios y el Estado. Fundación Pueblo Indio del Ecuador. Quito-Ecuador: Ediciones Abya-Yala, 1998.

TAULI-CORPUZ, Victoria. Prólogo. In: HUACO PALOMINO, Marco Antonio. Los trabajos preparatorios del Convenio no. 169 sobre Pueblos Indígenas y Tribales en Países Independientes. Fundación Konrad Adenauer (KAS), Programa Regional de Participación Política Indígena (PPI) en América Latina. Lima, 2015.

YRIGOYEN FAJARDO, Raquel. El derecho a la libre determinación del desarrollo, la participación, la consulta y el consentimiento. In: APARICIO, Marco (ed.). Los derechos de los pueblos indígenas a los recursos naturales y al territorio. Conflictos y desafios en América Latina. Lima-Perú: Icaria, 2011.

WALSH, Catherine. Interculturalidad crítica y (de)colonialidad. Ensayos desde Abya Yala. Quito: Instituto Científico de Culturas Indígenas, 2012.

WALSH, Catherine. Interculturalidad, Estado, Sociedad: Luchas (de)coloniales de nuestra época. Universidad Simón Bolívar, Ediciones Abya-Yala, Quito, marzo 2009. 